\title{
Endovascular reconstruction of primary coarctation in a 12-year- old boy technical consideration
}

\author{
Santosh Kumar Sinha, Puneet Aggarwal, Anupam Singh
}

Sinha SK, Aggarwal P, Singh A. Endovascular reconstruction of primary coarctation in a 12-year-old boy technical consideration. Curr Res Cardiol 2017;4(4):73-75.

\section{ABSTRACT}

Coarctation is a generalized disease which mainly manifests in aorta and presents as aortic coarctation. While transcatheter approaches have replaced surgery, there is still no consensus about the best among only balloon dilatation, aortic stent-grafts, self-expanding stent or balloon expandable stent. Here, we report a case of 12 -year-old boy who presented with hypertension in whom severe primary coarctation of thoracic aorta was diagnosed which was successfully treated with endovascular reconstruction using self-expandable stent. Stent migration is always an issue during deployment and which is minimized with rapid pacing and bringing down the blood pressure. We successfully performed the endovascular treatment without aid of pacing thereby bringing his blood pressure to near normal level with no further catch up on follow up. Therefore, balloon expandable stent is safe, minimally invasive, and effective treatment for thoracic coarctation.

Key Words: Thoracic coarctation; Endovascular reconstruction; Self expandable stent; Stent graft; Stent migration
Coarctation of the aorta $(\mathrm{CoA})$ accounts for $5 \%$ to $10 \%$ of all congenital cardiovascular malformations with, $90 \%$ mortality by fifth decade if left unrepaired, mean age being third decade (1). Various therapeutic options available which include surgery, balloon angioplasty and endovascular reconstruction (2). The endovascular approach for treating of both native and recurrent coarctation especially among adolescents and adults has become widely acceptable option since the mid-1990s, though optimal approach still remains debatable due to lack of randomized trials between the two. Peripheral balloon angioplasty has the potential to for injury to intima and part of the media with long term potential of recoil, restenosis and aneurysm formation although vessel diameter increases. Therefore, stent implantation scores over balloon angioplasty alone as its radial support to the vessel wall prevents above complication, with the future option of redilatation (especially in young patients), negating the need of over sizing which further avoids any major transmural injury $(3,4)$.

\section{CASE REPORT}

A 12-year-old boy presented with history of exertional dyspnoea (NYHA functional class II) of nine months duration. On physical examination, the blood pressure in both arms and both legs were 192/96 mmHg and 92/60 $\mathrm{mmHg}$ respectively by appropriately sized cuff. There was absent pulse on tibial and femoral arteries on both legs. Radio-femoral delay was appreciable with a pressure gradient of $100 \mathrm{~mm} \mathrm{Hg}$ between upper and lower extremities. Other examination findings were not remarkable. Routine haemogram and urine examination were normal. Electrocardiogram revealed left ventricular hypertrophy with mild ST-T changes. 2-D echocardiogram diagnosed a bicuspid aortic valve, left ventricular hypertrophy and normal ejection fraction. He was treated with antihypertensive drugs including amlodipine, losartan, chlorthalidone and prazopressin. A contrast computed tomographic angiogram showed a severe CoA of the descending thoracic aorta at level of the isthmus involving a $3-\mathrm{cm}$ long segment (Figures $1 \mathrm{~A}$ and 1B).

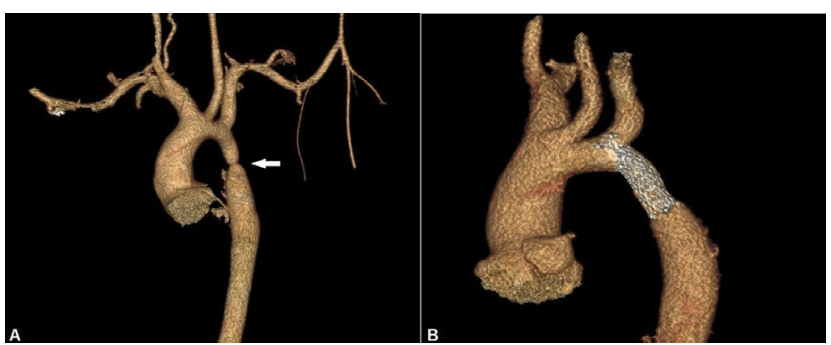

Figure 1) (A) MDCT image of severe thoracic coarctation; (B) Reconstructed image post endovascular reconstruction at 9 months
Catheter based angiogram was done through right radial route which showed severe $\mathrm{CoA}$ with profuse collaterals in its vicinity (Figures 2A and 2B).

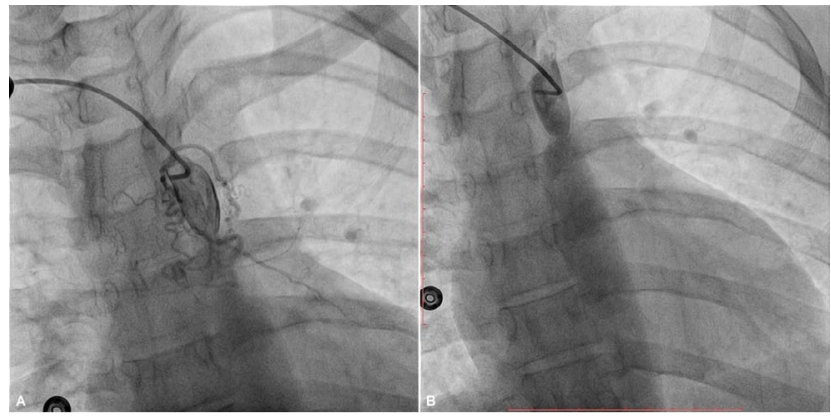

Figure 2) (A, B) Catheter based aortogram through transradial route showing severe thoracic coarctation with multiple collaterals

On further pull back, it showed a gradient of $100 \mathrm{mmHg}$. Endovascular approach was planned after informed consent. Access was gained by $6 \mathrm{~F}$ sheath through the right femoral artery (retrograde approach) using micro puncture set and $4000 \mathrm{U}$ of heparin was administered. 6F Judkins right (JR) catheter was advanced over 0.035 -inch straight tip Terumo wire (Terumo Inc, Japan) and lesion was crossed (Figure 3A).

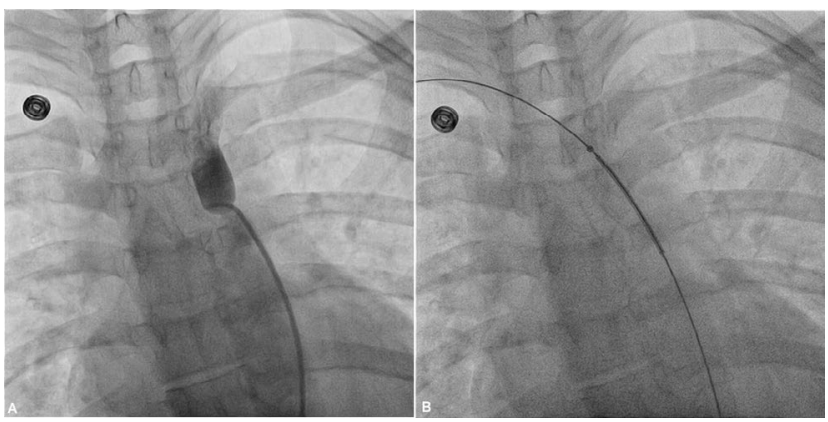

Figure 3) (A) Lesion crossed with judkins right catheter; (B) Stent delivered across the coarcted segment over superstiff Amplatz wire

JR catheter was advanced beyond the lesion and wire was exchanged with 0.035 " exchange length $(260 \mathrm{~cm})$ superstiff Amplatz guidewire (Meditech, USA). Predilatation was performed by $6 \mathrm{~mm} \times 40 \mathrm{~mm}$ Mustang balloon followed by $10 \mathrm{~mm} \times 40 \mathrm{~mm}$ Mustang balloon (Boston Scientific, USA)

Department of Cardiology, LPS Institute of Cardiology, G.S.V.M. Medical College, Kanpur, Uttar Pradesh, India

Correspondence: Dr Santosh Kumar Sinha, Department of Cardiology, LPS Institute of Cardiology, G.S.V.M. Medical College, Kanpur, Uttar Pradesh, India 208002. Telephone+91-0512-2556521, fax:+91-0512-2556199, e-mail fionasan@rediffmail.com

Received: September 20, 2017, Accepted: December 13, 2017, Published: December 15, 2017

OPEN ACCESS

This open-access article is distributed under the terms of the Creative Commons Attribution Non-Commercial License (CC BY-NC) (http:// creativecommons.org/licenses/by-nc/4.0/), which permits reuse, distribution and reproduction of the article, provided that the original work is properly cited and the reuse is restricted to noncommercial purposes. For commercial reuse, contact reprints@pulsus.com 
Pressure gradient trans-aorta after the balloon dilatation was $60 \mathrm{~mm} \mathrm{Hg}$. Nitroglycerin infusion was started $(15 \mathrm{mcg} / \mathrm{mint})$ to lower down the blood pressure. $12 \mathrm{~mm} \times 60 \mathrm{~mm}$ Epic self-expanding stent (Boston scientific, USA) was delivered across the lesion over the wire and gradually released by pulling the lock (Figure 3B). During deployment, wire-stent assembly was held firm as stent was getting migrated. During deployment, stent was also pulled in between to keep it across the lesion and this was performed thrice before final deployment. It was further post dilated with $12 \mathrm{~mm} \times 40 \mathrm{~mm}$ Mustang non-compliant balloon at 14 atm pressure (Figures 4A-4D).

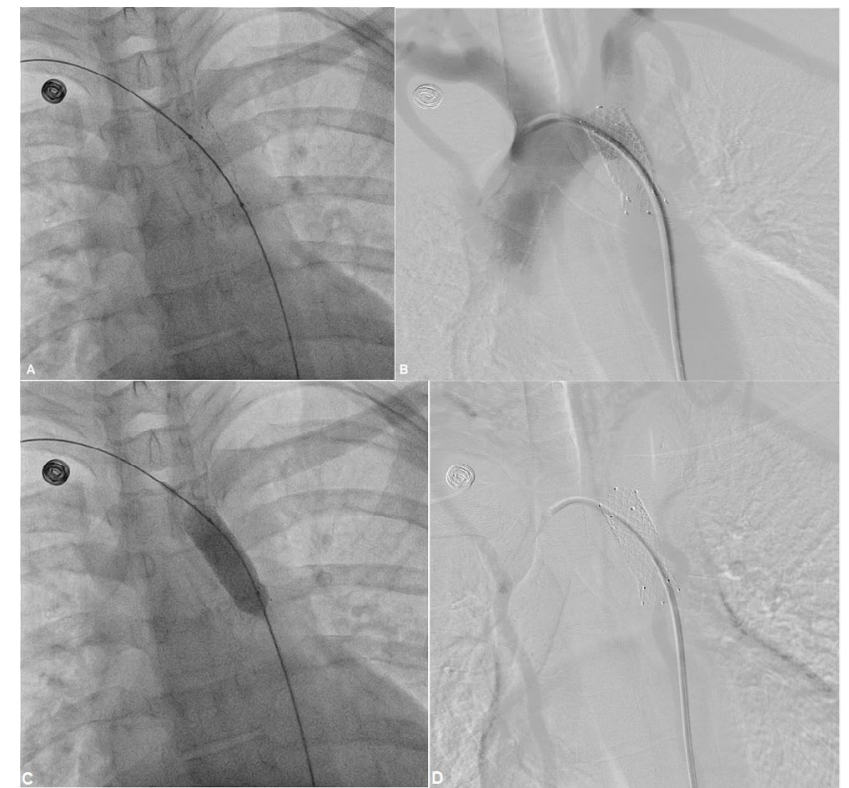

Figure 4) (A) Well deployed stent showing mild narrowing at the waist; (B) Digital subtraction angiogram (DSA) image showing mild narrowing at the distal edge; (C) Post dilatation of stent with non-compliant balloon; (D) Well apposed and well deployed stent

During catheter pull back, residual gradient was $3 \mathrm{~mm} \mathrm{Hg}$. Marked improvement in his symptoms were noted. His blood pressure was 152/80 $\mathrm{mmHg}$ with no appreciable gradient between the upper and lower extremities. Femoral and tibial pulses were palpable on both legs. Patient was started on aspirin $75 \mathrm{mg}$ once daily and was discharged with ramipril $5 \mathrm{mg}$. After 9-months' follow-up, blood pressure was stable at 136/60 $\mathrm{mmHg}$ and patient was asymptomatic and MDCT showed well deployed stent (Figure 1B).

\section{DISCUSSION}

The long-term complications of untreated CoA in adults include hypertension, premature coronary artery disease, sudden cardiac death, heart failure, endocarditis, rupture, dissection, aneurysm formation and stroke. Although surgical repair was the gold standard, it has now been replaced by endovascular reconstruction as surgery carries the risk of increased bleeding due to presence of significant intercostal collaterals, paradoxical hypertension, aortic dissection, left recurrent laryngeal nerve paralysis, phrenic nerve injury, and subclavian steal.

Outcomes with balloon angioplasty although shows good initial relief of stenosis but high rate of recoarctation and aneurysm formation therefore, stenting is preferred. Short term efficacy of stent implantation is well recognized, but accurate long term follows up assessment is sparse. Recent reports indicate potential physiological benefits stenting, including midterm left ventricular mass regression and long-axis function improvement, and amelioration in central aortic function with associated reduction of ambulatory systolic blood pressure (5-8).

$95 \%$ of patients don't require repeat intervention at 5 years, and short-term complications have been reported in $8.3 \%$ of patients among endovascular reconstruction group (9). The common long-term complications are edge dissection, aneurysm formation, re-coarctation or stent fracture (9-13). The recurrence of coarctation is attributed to the severity of the disease, fibrotic changes, cystic medial necrosis, intimal tear, thrombosis and graft-infolding in the involved redundant aortic segment due to over sizing during stent deployment. Therefore, stent should not be oversized as they remodel in long term and the purpose should be to abolish the gradient. Most of the available data suggest use of covered stent but it is very costly and not readily available, therefore we decided to use self-expanding stent (4). However, certain substrate warrants covered stents such as: subatretic coarctation, native coarctation associated with patent ductus arteriosus, re-coarctation combined with aneurysm formation (14). Sometimes, right ventricular pacing at fast rate (or rarely adenosine infusion) is employed during inflation to facilitate the precise stent placement (13). We used only nitroglycerin drip to lower down the blood pressure and deployed the stent without other aids. As stents remodel with time, post dilatation at high pressure using non-compliant balloon is not required except if a waist or any significant pressure gradient persists (12). Also, one should avoid flaring the ends of the stent with a larger balloon to attain geographical match with the dilated post-stenotic segment because there is no clear-cut evidence of any significant benefit, but it carries a real risk of stent migration or aneurysm formation as shown by Chessa et al. (12). The procedural success is defined as residual gradient $<10 \mathrm{mmHg}$, and an improvement in diameter to $90 \%$ of the normal adjacent aortic arch vessel (13).

\section{CONCLUSION}

The diameter and length of stent are most important factor for technical consideration as the stent must cover the affected segment, and at the same time proximal end not protruding into the left subclavian artery. The stent diameter must not exceed the diameter of the descending aorta at the level of the diaphragm which is considered as reference level in order to avoid aneurysm formation or rupture (4). Alternatively, the average diameter of the aortic isthmus (or transverse aortic arch) and the descending aorta at the level of diaphragm may also be considered. Also, the ratio of expanded stent diameter to that of coarcted segment is usually kept around 2-3.5 and should always be $<3.5$ to avoid aneurysm formation or dissection as stents remodel with time. The most important parameter should be relieving of pressure gradient. Therefore, endovascular reconstruction for thoracic coarctation with self-expanding stent is a safe and promising with acceptable alternative to surgical repair or balloon angioplasty alone.

\section{ACKNOWLEDGEMENT}

Vinay Singh-Radiation Safety Officer for his technical support in MDCT image reconstruction.

\section{CONFLICT OF INTEREST}

None

\section{REFERENCES}

1. Rosenthal E. Coarctation of the aorta from fetus to adult: curable condition or lifelong disease process? Heart. 2005;91:1495-502.

2. Godart F. Intravascular stenting for the treatment of coarctation of the aorta in adolescent and adult patients. Arch Cardiovascular Dis. 2011;104:627-35.

3. Tzifa A, Ewert P, Brzezinska-Rajszys G, et al. Covered Cheathamplatinum stents for aortic coarctation: Early and intermediate-term results. J Am Coll Cardiol. 2006;47:1457-63.

4. Golden AB, Hellenbrand WE. Coarctation of the aorta: Stenting in children and adults. Catheter Cardiovasc Interv. 2007;69:289-99.

5. Lam YY, Kaya MG, Li W. Effect of endovascular stenting of aortic coarctation on biventricular function in adults. Heart. 2007;93:1441-7.

6. Chen SS, Donald AE, Storry C, et al. Impact of aortic stenting on peripheral vascular function and daytime systolic blood pressure in adult coarctation. Heart. 2008;94:919-24.

7. Thanopoulos BV, Eleftherakis N, Tzanos K, et al. Stent implantation for adult aortic coarctation. J Am Coll Cardiol. 2008;52:1815-6.

8. Shennib H, Lopez JR, Ramaiah V, et al. Endovascular management of adult coarctaion and its complications: Intermediate results in a cohort of 22 patients. European J Cardiothorac Surg. 2010;37:322-7.

9. Forbes TJ, Kim DW, Du W, et al. Comparison of surgical, stent, and balloon angioplasty treatment of native coarctation of the aorta. An observational study by the CCISC (Congenital Cardiovascular Interventional Study Consortium). J Am Coll Cardiol. 2011;58:2664-74.

10. Holzer R, Qureshi S, Ghasemi A, et al. Stenting of aortic coarctation: acute, intermediate, and long-term results of a prospective multiinstitutional registry- Congenital Cardiovascular Interventional Study Consortium (CCISC). Catheter Cardiovasc Interv. 2010;76:553-63. 
11. Moltzer E, Roos-Hesselink JW, Yap SC, et al. Endovascular stenting for aortic (re)coarctation in adults. Neth Heart J. 2010;18:430-6.

12. Chessa M, Carrozza M, Butera G, et al. Results and mid-long-term follow-up of stent implantation for native and recurrent coarctation of the aorta. Eur Heart J. 2005;26:2728-32.

13. Tanous D, Collins N, Dehghani P, et al. Covered stents in the management of coarctation of the aorta in the adult: initial results and 1-year angiographic and hemodynamic follow-up. Int J Cardiol. 2010;140:287-95

14. Forbes TJ, Garekar S, Amin Z, et al. Procedural results and acute complications in stenting native and recurrent coarctation of the aorta in patients over 4 years of age: a multi-institutional study. Catheter Cardiovasc Interv. 2007;70:276-85. 